Volume 1, Issue 2, January 2021, Pages 38-45

DOI: $10.18775 /$ ijom.2757-0509.2020.12.4005

URL: http://dx.doi.org/10.18775/ijom.2757-0509.2020.12.4005

\title{
Strategic Decision Making: The Effects of Big Data
}

\author{
${ }^{1}$ Harvey C Turner, ${ }^{2}$ David Atkinson \\ ${ }^{1,2}$ Business \& Enterprise Management, Pearson Business School, United Kingdom
}

\begin{abstract}
This study aimed to understand the emerging effects big data is having across different business functions as well as how much the insights gathered, from big data sets, are starting to influence business strategy. The literature highlights a lack of understanding around big data, with very little research focusing on big data's applications outside of short-term marketing strategies. This research investigated the potential barriers to big data integration within businesses, and sought to understand how these could be removed. In order to achieve an in depth understanding, an interview based approach was used. A wide range of business sources were examined to further understand the gaps identified by previous research. Primary research took the form of in-depth interviews. Respondents were carefully selected based on industry knowledge and experience, working for companies such as Ebiquity PLC, Satalia and Barclays. The interviews were used to compare and contrast the experts' opinions and establish whether the key themes identified in the literature held true in the primary research. This approach enabled real insight to be gathered in order to concisely examine and critique the current literature as well as enabled further themes to be investigated. This investigation found how critical big data is becoming to business success, including understanding an emerging gulf between those who have adopted data big sets and those who have not. It was also understood that, on the whole, knowledge and understanding is lagging far behind benchmarks set by some businesses. The paper concludes by explaining why big data is not influencing business strategy. A focused understanding approach is outlined as the preferred solution to bridge the gulf between the 'haves' and 'have not's'.
\end{abstract}

Keywords: Big data, Business strategy, Big data integration, Business optimisation

\section{Introduction}

Big Data is a relatively recent term coined to describe large volumes of data that inundate businesses during their day to day operations (SAS, n.d.). Big Data can be used as modern data driven approach to business analysis, when utilised correctly it can enhance business decision making, leading to greater productivity, efficiency and financial results (Schloss, 2018). Many in the business world do not fully understand the application of Big Data neither do they fully understand how to define it. This has led to great divisions across businesses and industries in knowledge, there are the have's and have not's in terms of understanding, there are few businesses that truly understand the power of correlation analysis (Lock, 2012). At the core, Big Data insights are large scale correlations found from patterns held in the mined data. As the size of the data set increases, so too does the power of the insight gained (BBC News, 2017). The applications stretch across all sectors from healthcare to retail. This paper specifically focuses on Big Data's effects on full business strategy, not just independent effects on singular business functions, with the aim to examine whether Big Data analysis is being fully utilised by businesses. Much of the research surrounding Big Data has been into its effects on businesses, and more specifically how Big Data can influence short term marketing strategies. Including the analysis by $\mathrm{Xu}$ et al, who coined the fusion knowledge perspective after testing the effects of traditional marketing analytics against the use of Big Data analytics (Xu, Frankwick and Ramirez, 2015). Further to the apparent imbalance in previous research in terms of the effects Big Data can have, there is a varying concern from many academics about the true relevance of Big Data. Academics Barcos and Selbst in 2016 questioned the true effectiveness of the insights created, as any algorithms used to create the insight will inherit any prejudices the creator(s) held and any prejudices held within the data sets from those who the data was gathered from (Barcos \& Selbst, 2016). Hardford in 2014 penned an article asking 'if we are making a mistake with Big Data', the article outlined four key promises of those that champion Big Data and examined current business usage and potential. Within the article he examined key flaws in using Big Data to make decisions, using work by Speiglhalter among others he acknowledges that "there are a lot of small data problems 
that occur in Big Data, they don't disappear because you've got loads of stuff' (Speiglhalter, 2014). The article uses a non-business example (Google Flu) to highlight the potential flaws in Big Data analysis, driving home the point that its uses revolve around correlation insight not causation, and that often figuring out causation from data sets is nearly impossible. Hartford concluded that the necessary insights for Big Data have not arrived, but they are coming, with the major challenge being the ability to not make the classic statistical errors just on a larger scale (Harford, 2014).

It is for this reasoning; this paper seeks to understand the effectiveness and application of Big Data in terms of business strategy. The initial reading suggests that many businesses are simply not ready to adopt such tools to deliver better business insights, not just through a poor understanding of the technology involved, and a lack of basic understanding including and inability to accurately define Big Data. 'Computerweekly' conducted an online survey to examine the lack of understanding amongst businesses, interestingly, and adding further fuel to the fire that Big Data and marketing are tied at the hip the article states in its opening line "the most interesting point thrown up by the online survey is just how little understanding the marketing efforts around Big Data have managed to generate". This further illustrates how the applications of Big Data are being siloed into individual business functions, the survey did however reveal that under $20 \%$ of those surveyed understood the benefits of Big Data technologies.

With fewer than $10 \%$ understanding the storage solutions available, or feeling that consultancies out there are prepared enough to offer credible solutions. While understanding appears to be low, Lock indicates that of those few who have developed an understanding and begun to apply Big Data analysis confidence is high, with near $60 \%$ acknowledging that Big Data analysis has solved problems that were too expensive in the past, and 55\% stating Big Data analysis had enabled them to come up with new and improved solutions to problems (Lock, 2012). Trevor and Varcoe stated that for a business to have a successful business strategy they must have full 'enterprise alignment', which includes resource management, organisational capability understanding and full infrastructure management (Trevor and Varcoe, 2017). Businesses who excel at only selected business functions will be at a much higher risk of failure, with U.S statistics stating that $66 \%$ of businesses fail within two years due to poor strategy (Olsen, n.d.). After researching reasons why business strategies fail of the top 10, which include poor understanding of a market and consumers to lacklustre financial management and poor sales, all of them can benefit from Big Data analysis. Examples include: correlating sales against seasonal activity to predict cash flow (finance), or analysing like for like sales to understand which territory to invest in next (Marketing). It therefore becomes of paramount importance for a business to understand how Big Data can be applied across a business to create insights and advantages.

\section{Research Objectives}

The report will seek to establish what Big Data is in terms of a business analysis tool, how it can be used to make strategic decisions, and the relative industry effectiveness through a series of interviews.

1. Critically review the literature on Big Data and the use of Big Data in strategic decision making.

2. To investigate to what extent, and how Big Data is influencing strategic decisionmaking.

3. To understand the implications of using Big Data to influence decision making.

Discuss the influence of Big Data on strategic decision making, and make future recommendations for businesses to aid adoption, including recommendations for further research to influence this process.

\section{Literature Review}

'Big Data' (Mayer-Schönberger \& Cukier, 2013) acted as the first deep dive publication into the effects and revolutionary nature of Big Data. As found within the background evaluation of this project, a major 'sell' of Big Data's uses regard its ability to solve small challenges, but it really comes into its own when establishing correlations in large scale data sets. The publication cites Big Data analysis as a major future force in gaining competitive advantages, helping businesses to do what they already do, 'just better'. This is backed up by Gopalkrishan et al who listed Big Data analysis as the most valuable business asset and tool of the future, the report stated businesses are realising the importance in leveraging their data as a strategic asset (Gopalkrishan et al, 2012). An MIT management review entitled 'How Big Data is Different' went further than just providing an academic insight, and actually identified how businesses could gain value from Big Data and underlined further the new organisational capabilities it can 'unleash' (Davenport, Bart $\&$ Bean, 2012). In further reading to search for the origin of Big Data, the term first appeared in a slide deck in 1998, 
entitled 'Big Data and the next wave of infrastress' (Diebold, 2012). From this initial presentation the flood gates began to open, with the first academic publication coming in the same year discussing futuristic mining techniques (Weiss and Indrukya, 1998). However, these early adoptions of the term were very immature in their knowledge, and often had little understanding of the full benefits Big Data analysis could hold. Many academics played with the definition and understanding of Big Data architecture, but it was not until 2012 that the movement gathered real speed, with a specific global KDD conference on how to mine Big Data. The definition of Big Data to those in the industry became more solidified as the three V's (Volume, Variety \& Velocity) definition became more widely used (Fayyad, 1997). This 3 $\mathrm{V}$ model has since been adapted by many including Fan \& Bifet to include variability and value. This three or five V model has acted as the basis for many academics, businesses, health organisations and governments to understand Big Data, and assess where to find value in it. However, few have been able to apply their understanding into measurable results. The IDC reported that $23 \%$ of all of the data in existence would be useful if tagged and analysed, but currently only 3\% is currently being tagged and analysed (Gantz and Reinsel, 2018), a vast increase in the volume of data being collected has been reported throughout all of the academic literature with Fayyad reporting that Google has more than 1 billion searches a day, Twitter more than 250 million tweets a day and Facebook has more than 800 million updates a day (Fayyad, 1997). This explosion of recordable data runs throughout the literature, with Fan \& Bifet acknowledging the new array of data sources including revolutionary sensory data (Fan and Bifet, 2013). This forms the second V of the model, variety, with Katal et al noting one of the major differences between traditional data mining and Big Data mining is the need to develop mining techniques that can deal with 'raw, structured, semi-structured and even unstructured data' (Katal, Wazid and Goudar, 2013). Velocity concerns the speed at which data is gathered, with Katel et al suggesting many businesses current analysis methods not being able to keep up with the constant inflow of data let alone produce real time insights (which is often where major competitive advantages associated with Big Data are created. Much of the literature suggested that currently there is poor application and understanding of Big Data, with Mayer-Schönberger \& Cukier noting the use of Big Data only exists within 'narrow' categories (Mayer-Schönberger \& Cukier, 2013), Gopalkrishan et al added to the evidence that currently Big Data applications are almost exclusive to: 'improvement of customer service, product buying behaviour and promotional offers' (Gopalkrishan et al 2012). Through the research the evidence begins to mount that Big Data's effects are being limited by the short sighted approaches to its usage, McAfee \& Brnjolfsson concede that there is little more than reported evidence that Big Data improves business performance, so conducted a study of 330 businesses across many sectors. They found that on average, data driven businesses were 5\% more productive and 6\% more profitable. Highlighting US retail giant Sears in their research, Sears championed the use of Big Data to drive insightful promotional strategies, further adding to the argument or issue that currently is that Big Data analysis effectively sits in silos, with no roll out across an entire business (McAfee \& Brnjolfsson, 2012). It is at this juncture the importance of this research is shown, throughout all the reading it is apparent that Big Data analysis is not being integrated between business functions. Alfusouzan highlights the need for integration in Big Data, stating research by Forrester which claims $80 \%$ of the value to be gained from Big Data is found by integration (Alfusouzan, 2015). Business function integration is vital for good strategy delivery (Kunisch, Müller-Stewens and Campbell, 2014), and a business without a good strategy is up to 60\% less productive (Richard P. Rumelt, 2012), these two points sit at the heart of the need to research the influence of Big Data over business strategy). After understanding the merits of Big Data, and its business application along with the current literature in relation to strategy and business functions, it becomes important to understand the challenges to businesses that Big Data causes. Firstly, there is still discussion as to the exact relevance of Big Data. Fan \& Bifet outlined their key concerns with Big Data, which include: ‘is there a need to distinguish Big Data analysis and regular analysis?' (Fan and Bifet, 2013) This concern was not shared by other academics, but it is worth noting that Davenport et al suggested Big Data analysis within a business adds another level of IT complexity that few can afford. So will drive a 'gulf between the companies that have the ability to invest and those that do not' Davenport, Bart \& Bean, 2012). Following the relevance tact, the next challenge revolves around recency over size, they question whether value is not held in the size of the data store, but in the time frame it was captured. Courtney agreed with this analysis, as part of his paper 'The larging-up of Big Data' he stated from a small study that most industries would benefit from data streams that 'focus on recency over size', but admitted that the number of data streams would have to be 'significantly larger' than current data analysis insights to be of value (Courtney, 2012). In many cases the literature suggests that the current Big Data analysis tools are not up to scratch, Hadoop is the most wide spread technological solution, but as Taleb reported as the number of variables grow, the number of fake correlations do too. Leinweber proved this point by showing that the S\&P 500 stock index could be directly correlated to butter production in Bangladesh (Leinweber, 2007). On examining the exact techniques used to mine Big Data, academics agree that on the whole many techniques are easy to paralyse, and can't adapt quickly enough to change. Efron underlined the fragility in such systems, and amongst stating it was often hard enough to gather statistical significance from Big Data he outlined the fragility of Hadoop and MapReduce 
and without the correct data scientists the systems are almost pointless (Efron, 2017). Davenport et al described the importance of data scientists within businesses, they offered a three point differentiation strategy between business that have experienced success with integrating Big Data into their business, they argue the biggest factor is to make data scientists a core asset of the business operations (Davenport, Bart \& Bean, 2012). In summary, the literature has highlighted a few key issues and themes. The first is the poor understanding of Big Data analysis (Fayyad, 1997, Gopalkrishan et al, 2012), the second is that most of the current research and application examples occur within a few business functions chiefly marketing (Mayer-Schönberger \& Cukier, 2013, McAfee \& Brnjolfsson, 2012), following on from a disconnect in understanding and application there was a lot of research as to the actual merits of Big Data (Fan and Bifet, 2013) and then further research in how value is actually obtained from it, in terms of system and actually which businesses have the ability to benefit from it (Courtney, 2012, Davenport, Bart \& Bean, 2012 Leinweber, 2007). The summary of the literature review provides three core themes, upon investigating these themes in further reading at the point there became several clues as to the reasoning for the lack of research. The first hypothesis revolves around recency, Big Data is a new concept, so it is only natural that there is a limited amount of research available and therefore a lower level of business adoption. The second major hypothesis is cost, while only some of the research outlined cost, there are a plethora of news articles suggesting a major limitation to Big Data analysis is the cost associated. Finally, the third hypothesis revolves around ethics, it is not something analysed in the literature review because of the direction of study, but there are questions being raised in wider reading that question the effectiveness of data in relation to global law changes chiefly the role of GDPR.

\section{Findings/ Discussion/ Recommendations}

There were three interviewees:

- $\quad$ An AI/ Data specialist - respondent 1

- $\quad$ Data insight marketing specialist - respondent 2

- A Strategy specialist - respondent 3

Task one of this analysis, in respect to objective 2, is to investigate the extent in which Big Data is affecting strategic decision making. For a business to adopt an approach to a problem it needs to understand the problem and understand the tools it is using to design a solution (Zwilling, 2011). Understanding forms the first key theme in the findings and analysis, the literature review suggested that general understanding is poor throughout businesses and that there is a lack of an ability to accurately define Big Data (Gopalkrishan et al, 2012, Fan and Bifet, 2013, Fayyad, 1997). The primary research unsurprisingly proved that the respondents had a good base knowledge of what Big Data is:

- Respondent 1: "More data than you can process on a single machine; with business applications on a scale not previously seen"

- Respondent 2: “A generic term used to describe large quantities of data; if analysed correctly, can help deliver value to the processor".

- Respondent 3: "Breadth and depth; so many more aspects are being measured in our lives; so much more granularity"

This level of understanding widely outstrips a basic level of understanding, but what it does do is create three different interpretations of the most accepted definition (the $5 \mathrm{~V}$ model Usama Fayyad). An overarching key issue found in the background analysis and literature review was the poor application of Big Data within a business, perhaps much of this is to do with the inability to effectively define it.

"The most interesting point thrown up by the online survey is just how little understanding the marketing efforts around Big Data have managed to generate" - computerweekly.com.

Big Data is a relatively new concept in comparison to business strategy (first coined in 1998) (Diebold, 2012), each respondent agreed how important business strategy is and how vital it is to business success, there was increased symmetry in their answers all listing similar qualities (in bold) to define strategy:

- Respondent 1: "At the core of your business; staying true to the vision, mission and values; constantly adapting"

- Respondent 2: "Very important; continuous process, constantly iterating, reacting and reflecting" 
- Respondent 3: "It is the core of a business; at the heart of the business; short planning cycles should be utilised to react to markets"

From the literature, it was claimed that a business with a good strategy is 60\% more effective (Richard P. Rumelt, 2012), it is therefore not unreasonable to claim that the ability to accurately define a tool leads to greater productivity and application. This provides evidence that Big Data's affect on strategic decision making could be being halted by the lack of ability to accurately define it, further evidence suggests that it is at senior levels, and only in specialised roles that there is an understanding of Big Data (Buluswar et al., 2017), which is backed up the the results of the primary research which chose respondents based on criteria that related to their seniority (see methodology section). Scope of application is another major topic to effect the influence on decision making, two themes were drawn out by the literature:

1. There is a lack of examples (McAfee \& Brnjolfsson, 2012)

2. Most applications revolve around marketing functions (Gopalkrishan et al 2012).

Respondent 3 reiterated theme 1: "It would be nicer if there were more examples of Big Data we could draw that openly showed that Big Data has created a strategic advantage". Respondent 2 also validated theme two in his response to question 8 by highlighting the marketing industry as an industry that stands apart in its adoption rates: "It's hard not to point at the marketing industry. Consumer goods industries are quite good at this". The evidence presented in these two interviews, begins to accurately reinforce the literature and answer why there is very little written on the effects of Big Data on strategy, most of the evidence/examples for the use of Big Data are for marketing, so those without the knowledge of the wider range of applications it has only see its applications in that field. A potential reason for the lack of examples could be down to an answer given by respondent 3, when questioned about his involvement with Big Data in business he could not offer many examples of the work he has been involved in: "I cannot go into detail on specifics because I'm under a non-disclosure agreement". Perhaps when business stop becoming so secretive about their activities with customers data there will be a growth in application, on the 25th of May EU rulings are set to shake up how businesses can use and manage our data (EU GDPR Portal, n.d.), hopefully creating an more transparent environment. Respondent 2 offered the idea that: "GDPR is forcing companies to focus only on the data that matters. This will be good for them". Respondent 1 was more concise but stated: "it brings many positives in terms of openness". There seems to be no clear evidence as to the extent of Big Data's influence on decision making, the analysis above has found that the key issues brought up in the literature review have been validated by the primary research. Gopalkrishan et al showed the strength of Big Data within marketing, which was further validated by respondent 2 listing marketing as the most important industry/ function that Big Data exists in. Due to the fact that all respondents could not accurately define Big Data, regardless of their level of knowledge, the hypothesis was developed that influence cannot be achieved unless a tool can be more accurately defined, which was built on the idea that Big Data is a modern tool (Only being coined in 1998, Diebold), unlike business strategy which has had years to develop and understood further.

Due to this, the effects of traditional strategy and its influences are much greater with Rumelt stating that well executed strategy can lead to a $60 \%$ increase in productivity, with Big Data only only increasing productivity by $5 \%$ as found in McAfee \& Brnjolfsson's study, which provides numerical evidence for the hypothesis above (McAfee \& Brnjolfsson, 2012). Following establishing the effects Big Data is having on business strategy, the third objective revolves around the business implications of Big Data. All respondents were asked to what extent they believed that Big Data would effect future business strategy, the aim of this was to start to be able to define and understand how a business will need to prepare in the future:

- Respondent 1: "10- It is the future of decision making"

- Respondent 2: "6 - it's a big part of the future"

- Respondent 3: "If you're looking at big businesses (FTSE 250) it's an 8 or 9"

This shows a reasonable level of agreement between respondents that they believe Big Data will have an implication for future decision making, and further validates the need for this project. Moreover, it fills the gap created by the literature, on the one side you have McAfee \& Brnjolfsson, Alfusouzan, Kunisch, Müller-Stewens and Campbell outlining the merits of Big Data, without really digging into how to apply it. On the other side, there is Efron and Davenport et al explaining the business requirements in terms of technology and resources. There exists a gap needing to be bridged between what the merits and requirements mean for future application. The primary research identified some themes for 
the business implications of Big Data, the major of which is cost. Savitz analysed the business cost of Big Data and developed the following insight: "Big Data offers big business gains, but hidden costs and complexity present barriers that organizations will struggle with." (Savitz, 2012). Efron covered the basic technological tools involved with Big Data which include Hadoop and MapReduce, the same Forbes by Savitz article examined the cost of these individual tools and found they were actually helping to drive the costs of Big Data down as "Hadoop, which parallelizes large data sets across low-cost commodity hardware for easy scale is dramatically reducing the cost of petabyte environments." (Savitz, 2012). While none of the respondents went into detail about specific costs or tools they all did in part make reference to the cost of Big Data:

- Respondent 1: "It's often a question of cost and ability, there are very few business with the right resources to capitalise on the potential gains"

- Respondent 2: "In my experience cost is a large draw back for many"

- Respondent 3: "Working with smaller businesses, I can see no way that they would be able to utilise Big Data to generate insights in the near future because they simply don't have the resources"

Both the primary and secondary research acknowledged that the first implication for a business looking to utilise Big Data, will be the cost of the technology. The second large cost will be in terms of talent acquisition, which Davenport et al outlined in his report about the importance of data scientists. Respondent 1 also acknowledged the need for talent acquisition: "The hard part will be attracting talent". McKinsey Global identified that there would be a global shortage of around 250,000 data scientists by 2024 (Henke et al., 2016), only furthering the current demand and increasing wages. According to Glassdoor the average data scientist in the U.K earns around $£ 113,000$ annually, representing these skills come at a premium cost to a business when compared to traditional business roles (Glassdoor.co.uk, 2018). These two examples of technology and HR explicitly define the major cost implication for a business. But what happens if businesses don't embrace Big Data? Respondent 1 was very clear on this he stated that: "Companies that embrace these technologies will be the ones who win, regardless of industry". This raises further questions about the need for Big Data. As seen above, all the respondents and the literature suggests that Big Data insight analysis will at least in some part be vital to future decision making, but at what point is there a return on investment? Respondent 3 provided a useful opening argument: "I do think it will be a while before it [Big Data] becomes a hygiene factor, rather than a differentiator". Utilising Herzberg's model of differentiators $v$ hygiene factors, which suggests that for a business to be competitive it must satisfy all hygiene factors in a market but to be a leader and experience increased success it must differentiate itself somehow. Currently as respondent 1 stated those who differentiate by utilising Big Data "will win" (Herzberg, 1959). It is difficult to establish at what point there is an exact return on investment for Big Data, due in part to the aforementioned secrecy that surround data practises in business. However, analysis by ICAS has found 10 businesses that are using Big Data analytics to gain a competitive advantage through using the tool as a differentiator (O'Neill, 2016). These include: American Express, Amazon, Netflix, BDO, Capital One and Starbucks, each of these businesses are redefining their own markets through the use of Big Data, illustrating the potential implications of using Big Data on decision making. The examples identified by ICAS, provide a basis to cover objective four of this project, the companies listed above have the resources available but also have been focussed in their approaches. This is how they have generated their competitive advantages. This objective is primarily concerned with providing future recommendations for businesses, and outlining where further research would be necessary. Through the work by Savitz, and the themes of HR and cost identified above, this report can identify the major recommendation as:

\section{Big Data: The Devil is in the Detail-Applying Focused Understanding}

The major implications for Big Data as outlined above stem from cost and resource availability. Efron and Davenport et al described the basic requirements for a business to get a foothold on the Big Data ladder, the analysis of Savitz's work further developed the picture as to what it costs a business financially to begin utilising Big Data. But, simply having the liquid assets to invest in the hardware and people power required is not enough. Respondent 2 identified that "you need to combine it [Big Data] with other things" for it to be the future of decision making. Forbes stated that at the end of 2017, 53\% of companies were adopting Big Data analytics, with telecom and finance businesses leading the way (Colombus, 2017), this illustrates a marked increase in adoption rates for businesses, but as McAfee \& Brnjolfsson's found during their cross industry study, Big Data insights were only increasing productivity by $5 \%$ and profitability by $6 \%$ (McAfee \& Brnjolfsson, 2012). This raises many questions as to whether it is currently worth investing in Big Data 
analytics, when more simplistic, better understood tools such as introducing more integrated business strategies can provide greater returns (up to $60 \%$ increases in productivity) (Richard P. Rumelt, 2012). The power of developing integrated strategies was also backed up by the primary research with respondent 1 describing the need for integration as "critical". It appears there is a need to focus, for two reasons. Firstly to bring the cost of Big Data analysis down and secondly to increase its effectiveness. Respondent 2 highlighted the overall need for focus: "Too many people are obsessed with data and not the decisions that can be made or actions that can be taken off the back of it". This reports overall recommendation to mitigate the lack of focus is to develop greater understanding. This returns to the original theme of the findings section of this report, that identified a lack of understanding in the literature (Gopalkrishan et al, 2012, Fan and Bifet, 2013, Fayyad, 1997), and a lack of ability to accurately define Big Data, as proved by the answers generated in the qualitative interviews. It is our belief that through increased understanding, many of the issues discussed that are holding back the influence of Big Data, specifically on strategy will be removed. The increased focus will reduce the costs associated with mining and storing the data as highlighted by Savitz. Respondent 2 referenced focus as an advantage of the upcoming law changes in Europe: "GDPR is forcing companies to focus only on the data that matters. This will be good for them". We believe that the increased focus will bridge the gap between the 'have's and have not's' as defined by respondent 3 and Lock, because with increased understanding, there will be an increase in focus which reduces the resource requirements for smaller businesses and makes the tool more accessible. (Lock, 2012). This concludes the findings and recommendations section of this report, the last action is to define future research. Following on from the recommendation of understanding, the next project we will research in this field will revolve around understanding; how to improve dissemination of knowledge within a business, and assess how to best educate staff on how to apply Big Data and reap the rewards it can offer. In an attempt to increase the figures of productivity and profitability currently found by McAfee and Brynjolfsson. (McAfee and Brynjolfsson, 2012)

\section{References}

- Alfouzan (2015). Big Data In Business. ISJER, [online] 6(5). Available at: https://www.ijser.org/researchpaper/BigData-In-Business-2015.pdf [Accessed 29 Apr. 2018].

- Aronson, J. (1995). A Pragmatic View of Thematic Analysis | Qualitative Research | Ethnography. [online] Scribd. Available at: https://www.scribd.com/document/351813113/A-Pragmatic-View-of-Thematic-Analysis [Accessed 29 Apr. 2018]. $\underline{\text { Crossref }}$

- BBC News. (2017). Power of Big Data - BBC News. [online] Available at: http://www.bbc.co.uk/news/business29147254 [Accessed 28 Apr. 2018].

- Bohnet, I. (2016). How to Take the Bias Out of Interviews. [online] Harvard Business Review. Available at: https://hbr.org/2016/04/how-to-take-the-bias-out-of-interviews [Accessed 28 Apr. 2018].

- Braun, V. and Clarke, V. (2006). Using thematic analysis in psychology. Qualitative Research in Psychology, 3(2). $\underline{\text { Crossref }}$

- Buluswar, Campisi, Gupta, Karu, Nilson and Sigala (2017). How companies are using Big Data and analytics. [online] McKinsey \& Company. Available at: https://www.mckinsey.com/business-functions/mckinsey-analytics/our-insights/how- companies-are-using-big-data-and-analytics [Accessed 28 Apr. 2018].

- Colombus, L. (2017). 53\% Of Companies Are Adopting Big Data Analytics. [online] Forbes. Available at: https://www.forbes.com/sites/louiscolumbus/2017/12/24/53-of- $\quad$ companies-are-adopting-big-data-analytics/\#3fe606de39a1 [Accessed 28 Apr. 2018].

- Courtney, M. (2012). The larging-up of big data. Engineering \& Technology, 7(8). Crossref

- Davenport, T. H., Barth, P., \& Bean, R. (2012). How big data is different. MIT Sloan Management Review, 54(1), 43-46. Retrieved from https://search.proquest.com/docview/1124397830?accountid=48126

- Debois, S. (n.d.). 9 Advantages and Disadvantages of Questionnaires - Survey Anyplace. [online] Survey Anyplace. Available at: https://surveyanyplace.com/questionnaire-pros- and-cons/ [Accessed 28 Apr. 2018].

- Diebold, F. (2012). A Personal Perspective on the Origin(s) and Development of 'Big Data': The Phenomenon, the Term, and the Discipline, Second Version. SSRN Electronic Journal. Crossref

- Edwards, R. and Holland, J. (2013). What is qualitative interviewing?. 1st ed. London: Bloomsbury.

- Efron, B. (2017). Computer age statistical inference. New York: Cambridge University Press. Crossref

- EU GDPR Portal. (n.d.). EU GDPR Information Portal. [online] Available at: https://www.eugdpr.org [Accessed 28 Apr. 2018].

- Fan, W. and Bifet, A. (2013). Mining big data. ACM SIGKDD Explorations Newsletter, 14(2). Crossref

- Fayyad, U. (1997). Data mining and KDD: Promise and challenges. Future Generation Computer Systems, 13(2-3). $\underline{\text { Crossref }}$ 
- Flick, von Kardorff and Steinke (2004). [online] Available at: https://www.researchgate.net/profile/Stephan_Wolff2/publication/305496229_Wolff_in_F lick_et_a/links/5792046008aec89db77fca3c/Wolff-inFlick-et-a.pdf\#page=268 [Accessed 6 Mar. 2018].

- Gantz and Reinsel (2018). THE DIGITAL UNIVERSE IN 2020: Big Data, Bigger Digital Shadows, and Biggest Growth in the Far East. [online] Available at: https://www.emc.com/collateral/analyst-reports/idc-the-digital-universe-in-2020.pdf [Accessed 29 Apr. 2018].

- Glassdoor.co.uk. (2018). Salary: Data Scientist | Glassdoor.co.uk. [online] Available at: https://www.glassdoor.co.uk/Salaries/data-scientist-salary- SRCH_KO0,14.htm?countryRedirect=true [Accessed 28 Apr. 2018].

- Gopalkrishnan, V., Steier, D., Lewis, H. and Guszcza, J. (2012). Big Data, big business. Proceedings of the 1st International Workshop on Big Data, Streams and Heterogeneous Source Mining Algorithms, Systems, Programming Models and Applications - BigMine '12. $\underline{\text { Crossref }}$

- Harford (2014). Big Data: are we making a big mistake?. [online] Ft.com. Available at: https://www.ft.com/content/21a6e7d8-b479-11e3-a09a-00144feabdc0 [Accessed 6 Mar. 2018].

- Henke, Bughin, Chui, Manyika, Saleh, Wiseman and Sethupathy (2016). The age of analytics:Competing in a datadriven world. [online] McKinsey \& Company. Available at: https://www.mckinsey.com/business-functions/mckinsey-analytics/our-insights/the-age- of-analytics-competing-in-a-data-driven-world [Accessed 28 Apr. 2018].

- Herzberg, F. (1959). The motivation to work. New York: Wiley [u.a.].

- International Journal of Advertising, 33(1).

- John Walker, S. (2014). Big Data: A Revolution That Will Transform How We Live, Work, and Think. Crossref

- Katal, A., Wazid, M. and Goudar, R. (2013). Big data: Issues, challenges, tools and Good practices. 2013 Sixth International Conference on Contemporary Computing (IC3). Crossref

- Leinweber, D. (2007). Stupid Data Miner Tricks. The Journal of Investing, 16(1). Crossref

- Lock, T. (2012). Lack of understanding inhibits Big Data adoption. [online] ComputerWeekly.com. Available at: https://www.computerweekly.com/opinion/Lack-of-understanding-inhibits-big-data- adoption [Accessed 28 Apr. 2018].

- Louise Barriball, K. and While, A. (1994). Collecting data using a semi-structured interview: a discussion paper. Journal of Advanced Nursing, 19(2). Crossref

- Mayer-Schönberger, V. and Cukier, K. (2014). Big Data. Boston: Mariner Books.

- McAfee and Brynjolfsson (2012). Big Data: The Management Revolution. [online] Harvard Business Review. Available at: https://hbr.org/2012/10/big-data-the-management-revolution [Accessed 6 Mar. 2018].

- Olsen, E. (n.d.). Ten Common Causes of Business Failure. [online] OnStrategy. Available at: https://onstrategyhq.com/resources/ten-common-causes-of-business-failure/ [Accessed 28 Apr. 2018].

- O'Neill, E. (2016). 10 companies using big data. [online] Icas.com. Available at: https://www.icas.com/ca-todaynews/10-companies-using-big-data [Accessed 28 Apr. 2018].

- Provost, F. and Fawcett, T. (2013). Data Science and its Relationship to Big Data and Data- Driven Decision Making. Big Data, 1(1). Crossref

- S.M.Weiss and N. Indurkhya. Predictive data mining: a practical guide. Morgan Kaufmann Publishers Inc.,San Francisco, CA, USA, 1998.

- SAS (n.d.). What is Big Data and why it matters. [online] Sas.com. Available at: https://www.sas.com/en_gb/insights/big-data/what-is-big-data.html\# [Accessed 6 Mar. 2018].

- Savitz, E. (2012). The Big Cost Of Big Data. [online] Forbes. Available at: https://www.forbes.com/sites/ciocentral/2012/04/16/the-big-cost-of-big- data/\#77373e075a3b [Accessed 28 Apr. 2018].

- Schloss, J. (2018). Three Major Benefits of Big Data | Datameer. [online] Datameer.com. Available at: https://www.datameer.com/blog/three-major-benefits-big-data/ [Accessed 28 Apr. 2018].

- Spiegelhalter (2014). Spiegelhalter on Big Data. [online] Causeweb.org. Available at: https://www.causeweb.org/cause/resources/library/r12646 [Accessed 6 Mar. 2018].

- Sullivan, D. (2012). The Top 30 Most Common (and Critical) Interview Problems. [online] ERE Media. Available at: https://www.tlnt.com/the-top-30-most-common-and-critical- interview-problems/ [Accessed 28 Apr. 2018].

- Trevor, J. and Varcoe, B. (2017). How Aligned Is Your Organization?. [online] Harvard Business Review. Available at: https://hbr.org/2017/02/how-aligned-is-your-organization [Accessed 28 Apr. 2018].

- Xu, Z., Frankwick, G. and Ramirez, E. (2015). Effects of Big Data analytics and traditional marketing analytics on new product success: A knowledge fusion perspective. Crossref

- Zwilling, M. (2011). Nine Steps to Effective Business Problem Solving. [online] Business Insider. Available at: http://www.businessinsider.com/nine-steps-to-effective-business- problem-solving-2011-7? IR=T [Accessed 28 Apr. 2018]. 